\title{
KONSTRUKSI SOSIAL PERKAMPUNGAN BUDAYA BETAWI SETU BABAKAN DALAM KEHIDUPAN SEHARI-HARI
}

\author{
$1^{\text {st }}$ Herliyana Rosalinda, 2nd Pandu Pramudita, $3^{\text {th }}$ Enny Nurcahyawati \\ Universitas Indraprasta PGRI, Jakarta, Indonesia
}

\begin{abstract}
Abstrak. Betawi, kebudayaan masyarakat asli di wilayah Jakarta, lahir melalui proses historis dan sosiokultural yang panjang. Dalam proses perkembangannya, kebudayaan Betawi terus-menerus mengalami perjumpaan dengan budayabudaya lain yang berdatangan ke wilayah Jakarta. Perkampungan Budaya Betawi Setu Babakan dapat dibaca sebagai sebuah penanda bahwa budaya Betawi telah menjadi suatu budaya yang mulai 'dimuseumkan' demi menjaga kelestariannya. Penelitian ini bertujuan untuk mengetahui konstruksi sosial di Perkampungan Budaya Betawi Setu Babakan. Penelitian ini menggunakan pendekatan fenomenologi yang memungkinkan peneliti menggali lebih dalam dengan masuk sebagai pengamat sekaligus partisipan dalam kehidupan sosial di wilayah tersebut. Perkampungan Budaya Betawi Setu Babakan adalah wujud kehidupan sehari-hari yang dibentuk secara dialektis oleh komunitas Betawi, Pemerintah Provinsi DKI Jakarta, dan masyarakat Srengseng Sawah.
\end{abstract}

Kata kunci: konstruksi sosial, fenomenologi, Perkampungan Budaya Betawi Setu Babakan.

\begin{abstract}
Betawi, the culture of indigenous people in Jakarta, was born through a long historical and sociocultural process. During its development process, Betawi culture has been encountering other cultures that come to Jakarta. The existence of Betawi's cultural village of Setu Babakan can be read as a sign that Betawi has been considered as a culture that has to be 'put in museum' for the sake of its preservation. This study aims to understand the social construction in the Betawi's cultural village of Setu Babakan. This study uses phenomenological approach, since it enables researchers to dig deeper by entering social life in the area as an observer and participant at the same time. The Betawi's cultural village of Setu Babakan is an expression of daily life that is constructed dialectically by Betawi community, Provincial Government of DKI Jakarta, and other community in Srengseng Sawah.
\end{abstract}

Keywords: social construction, phenomenology, Betawi's cultural village of Setu Babakan.

Correspondence author: Pandu Pramudita, pandu.pramudita11@gmail.com, Indonesia 


\section{PENDAHULUAN}

Betawi, sebuah kebudayaan yang muncul dan berkembang di wilayah Jakarta dan menjadi bagian erat dalam kehidupan masyarakat Jakarta. Nama Betawi berasal dari kata Batavia, nama kota yang diberikan oleh VOC setelah berhasil merebut Jayakarta dari Kesultanan Banten dan mendudukinya pada 1619. Secara budaya, masyarakat Betawi merupakan hasil asimilasi dari berbagai suku bangsa, seperti Melayu, Arab, Cina, Jawa, Sunda, dan lain-lain, mengingat bahwa daerah ini sudah menjadi kota perdagangan yang ramai sejak abad ke-16 dan bahkan mungkin jauh sebelum itu.

Kapan Betawi mulai menjadi corak kebudayaan tersendiri di Nusantara masih menjadi bahan perdebatan di antara para peneliti sejarah. Akan tetapi, hampir pasti bahwa kelahiran budaya Betawi melalui proses yang panjang dan lama. Sejarah pembentukannya melalui sebuah proses dialektik yang melibatkan intelektualintelektual tradisional, termasuk budayawan dan seniman, yang membentuk tata aturan sebagai dasar pembentukan budaya Betawi yang kemudian diserap oleh masyarakat. Seiring waktu, proses panjang ini juga mengalami dinamika akibat perjumpaan yang terus-menerus dengan budaya-budaya lain yang berdatangan ke wilayah Jakarta. Meningkatnya arus urbanisasi ke Jakarta berdampak salah satunya pada banyaknya masyarakat Betawi yang sedikit demi sedikit terdesak dan 'minggir' ke daerah 'pinggiran'.

Keberadaan Perkampungan Budaya Betawi (PBB) Setu Babakan yang didirikan pada tahun 2000 dapat dibaca sebagai sebuah penanda bagi para intelektual, baik tradisional maupun modern, bahwa budaya Betawi telah menjadi suatu budaya yang mulai 'dimuseumkan'. Di satu sisi, pendirian PBB Setu Babakan oleh Pemerintah Provinsi DKI Jakarta dapat dimaknai sebagai upaya pelestarian budaya dan rujukan budaya Betawi. Namun di sisi lain, keberadaannya juga menunjukkan bahwa telah terjadi desakan hebat yang mengharuskan upaya penyelamatan aset budaya Betawi. Aset budaya yang dimaksud, dalam hal ini terkait struktur sosial dan struktur budaya yang dimiliki oleh masyarakat Betawi.

Struktur sosial adalah sebuah perangkat sosial yang harus dipahami oleh setiap anggota masyarakat untuk memainkan peran sosial mereka. Hal ini penting untuk dikaji sebagai pedoman generasi penerus sebuah masyarakat. Pengkajian struktur sosial di PBB Setu Babakan merujuk pada penggalian struktur sosial yang dapat digunakan oleh generasi muda dalam menentukan peran mereka sebagai masyarakat Betawi. Di sisi lain, struktur budaya juga penting untuk diungkap karena identitas kebudayaan perlu dipertahankan untuk menunjukkan posisi kebudayaan yang bersangkutan dalam konteks yang lebih luas, yakni multikulturalisme bangsa Indonesia. Penelitian ini bertujuan untuk mengetahui konstruksi sosial PBB Setu Babakan yang dibentuk oleh masyarakat Betawi di daerah tersebut, Pemprov DKI Jakarta, dan kelompok-kelompok masyarakat lain di wilayah Srengseng Sawah.

\section{METODE PENELITIAN}

Penelitian ini menggunakan pendekatan fenomenologi. Fenomenologi yang digunakan dalam penelitian ini adalah fenomenologi yang diungkapkan oleh Edmund 
Husserl. Konsep-konsep fenomenologi yang akan digunakan sebagai metode dalam penelitian ini antara lain intersubjektivitas dan epoche. Intersubjektivitas adalah membangun pengalaman diri bersama dengan orang lain (Pramudita 47-48). Pada pengalaman subjektif, pengalaman pada dasarnya terjadi terhadap orang lain, sementara posisi diri adalah sebatas melihat atau mendengar. Adapun pada pengalaman intersubjektif, subjek turut membangun kesadaran atas pengalaman orang tersebut, sehingga pengalaman yang mereka miliki secara tidak langsung menjadi pengalaman milik kita juga. Epoché merupakan metode yang ditawarkan oleh Husserl dalam membongkar karakteristik-karakteristik yang diberikan oleh ilmuwan sosial terhadap manusia, yang mengabaikan karakteristik-karakteristik unik yang dimiliki oleh manusia dalam interaksi sosial (Abercrombie et al. 413). Secara hemat, epoche adalah proses penundaan, yaitu menunda hal-hal yang tampak dan merenungkannya sejenak untuk mendapatkan makna-makna yang terdapat pada halhal yang ada di balik hal-hal yang tampak.

\section{HASIL DAN PEMBAHASAN}

\section{Masyarakat Betawi}

Nama Betawi dipergunakan sebagai nama suku bangsa setelah J. P. Coen menaklukkan Keraton Jayakarta pada 1619 dan memberi nama kota ini Batavia. Secara tertulis sebutan orang Betawi pertama kali terdapat dalam dokumen tahun 1644, berupa testamen Nyai Inqua, janda tuan tanah Souw Beng Kong, Kapiten Tionghoa pertama di Batavia. Nyai Inqua menyebut seorang pembantu perempuannya adalah orang Betawi (Saidi 95). Dalam kitab Sejarah Banten disebutkan istilah wong Jakerta. Gubernur Jenderal VOC J. P. Coen sendiri pernah mempergunakan nama Jacerta, sebelum ia menetapkan nama Batavia. Meski nama wong Jakerta atau orang Betawi baru dikenal pada abad ke-17, tetapi menurut (Saidi 97), suku bangsa di kawasan yang disebut Nusa Kalapa tersebut sudah berkelompok paling sedikit sejak 3.000 tahun yang lalu dan sebelumnya memang belum ada namanya.

Pendapat yang cukup berbeda dipaparkan oleh Rahmani (Rahmani). Menurutnya, kata Betawi diambil dari kata Fatawi, yaitu nama suatu golongan yang terdiri dari 40 orang. Orang-orang ini adalah pembawa fatwa dari panglima Fatahilah; dari 40 orang ini dibagi menjadi lima bagian sesuai dengan keahlian mereka, yaitu ahli strategi, ahli politik, mata-mata, agama, dan ekonomi. Mereka menyatakan diri sebagai kaum Fatawi-orang Betawi menyebutnya dengan kaum Betawi, dengan mengubah kata Fa menjadi Be (Rahmani 16). Adapun menurut Hidayah, Betawi berasal dari kata Batavia, yaitu nama kota Jakarta pada zaman penjajahan Belanda (Hidayah 79). Batavia sendiri adalah nama pengganti kota Jacatra yang telah dihancurkan oleh Jan Pieterzoon Coen, yang kemudian olehnya dijadikan tempat semua perintah dan kebijakan yang berlaku terhadap semua wilayah VOC (Verenigde Oost-Indische Compagnie) di Asia (Taylor 4).

Terdapat sebutan "orang Melayu Jawa" untuk komunitas penduduk di Jawa (Nusa Kalapa) yang berbahasa Melayu, dan kelompok suku bangsa ini kemudian hari disebut sebagai orang Betawi. Jadi, sebelum munculnya sebutan orang Betawi, dikenal beberapa sebutan untuk suku bangsa yang kemudian dikenal sebagai orang Betawi. Mereka disebut orang Jawa, orang Melayu Jawa, atau orang Jaketra. Sebutan lainnya 
mengacu pada agama yang dianutnya, di mana mereka dulu disebut sebagai orang Selam. Selanjutnya, tampaknya sulit untuk mengetahui sebutan lain di luar yang sudah diuraikan ini (Erwantoro 10).

Perkembangan Jakarta yang cukup pesat telah menghadirkan tantangantantangan tersendiri bagi masyarakat Betawi. Sebagai ibu kota negara, Jakarta menjadi magnet bagi orang-orang dari berbagai daerah untuk berdatangan dan kemudian menetap tinggal di sana. Hasilnya, banyak orang Betawi menjual tanah mereka sebagai kegiatan ekonomi praktis yang menguntungkan dan pergi ke daerah pinggiranpinggiran ibu kota negara ini. Hal ini, meskipun lambat, namun sudah disadari sejak lama oleh pemerintah DKI Jakarta yang ingin mempertahankan kebudayaan daerah asli kota ini. Program kawasan cagar budaya dilakukan oleh pemerintahan Ali Sadikin yang mengusung Condet sebagai kawasan pertanian yang berciri khas Betawi dan memiliki rumah-rumah tradisional yang dianggap sebagai bangunan-bangunan sejarah yang harus dipelihara (Windarsih 189).

Meskipun demikian, usaha Ali Sadikin tidak dapat berjalan seperti yang diharapkannya. Banyak orang Condet yang berada dalam kawasan cagar budaya memilih untuk menjual tanahnya dengan berbagai alasan, khususnya alasan ekonomi praktis yang menguntungkan bagi mereka (Windarsih 191). Namun nampaknya pemerintah Jakarta tidak begitu saja melepaskan masyarakat pergi dari wilayah ini. Perda No. 3 Tahun 2005 menetapkan Perkampungan Budaya Betawi berlokasi di Kelurahan Srengseng Sawah; Setu Babakan termasuk ke dalam kawasan ini (Windarsih 192). Keberadaan Kampung Betawi Setu Babakan menjadi penting dan strategis bagi pengembangan kesenian dan budaya Betawi sebagai jati diri Kota Jakarta (Murtani 283). Hal serupa diungkapkan oleh Megawanti (238), bahwa adanya Perkampungan Budaya Betawi membawa 'angin segar' bagi masyarakat Betawi untuk dapat mempertahankan kebudayaan Betawi.

\section{Perkampungan Budaya Betawi Setu Babakan}

Perkampungan Budaya Betawi Setu Babakan berada di Kelurahan Srengseng Sawah, Kecamatan Jagakarsa, Jakarta Selatan. Ini adalah perkampungan yang kesekian kali dibentuk oleh pemerintah dan masyarakat komunitas Betawi untuk membentuk sebuah 'cagar budaya' demi lestarinya kebudayaan Betawi. Namun demikian, tidak mudah untuk membentuk sebuah perkampungan budaya. Selain membutuhkan dana, hal yang lebih sulit adalah membentuk budaya. Terlebih, pada dasarnya masyarakat Kelurahan Srengseng Sawah tidak semuanya adalah masyarakat Betawi. Justru sebagian besar dari mereka bukan Betawi. Hal ini pernah disampaikan oleh Malik, yang mengatakan bahwa di Setu Babakan yang komunitasnya sudah banyak tidak hanya berasal dari Betawi, dirasakan sangat sulit bahkan untuk menyamakan tepinya atap rumah dengan gigi balang atau dalam menerima beberapa sentuhan budaya Betawi di bagian pagar halaman atau pintu rumah masing-masing warga (Malik).

Sebagai perkampungan yang dibentuk, Perkampungan Budaya Betawi Setu Babakan memiliki dua wilayah atau yang disebut oleh pengelola perkampungan sebagai 'zona', yaitu zona dinamis dan zona statis. Zona dinamis adalah zona atau wilayah dalam kawasan perkampungan budaya yang merupakan lingkungan alami atau yang bukan merupakan bagian perencanaan kawasan Perkampungan Budaya Betawi Setu Babakan (Windarsih). Zona yang dimaksud adalah kawasan pemukiman warga. Meskipun disebut sebagai lingkungan alami dan tidak termasuk dalam 
masterplan, pihak pengelola perkampungan budaya, yang bukan bagian dari pemerintah setempat, secara tidak langsung turut campur tangan atas zona ini. Mereka berusaha menghimbau masyarakat untuk membentuk atau setidaknya menggunakan ornamen rumah adat orang Betawi, seperti penggunaan gigi balang di tepian atap rumah. Hasilnya, banyak rumah-rumah modern yang telah berdiri di kawasan ini, yang tidak didasarkan atas konstruksi bangunan adat rumah Betawi namun tetap menggunakan gigi balang sebagai ciri khas rumah adat Betawi.

Adapun zona statis meliputi zona kesenian, yaitu areal yang memuat dan menampung kesenian Betawi seperti tari, drama, musik; zona sejarah atau areal yang memuat dan menampung budaya Betawi; zona wisata agro, yaitu areal yang berada dalam kawasan PBB baik berupa lahan kosong yang dimiliki oleh warga setempat maupun lahan yang dibebaskan oleh pemerintah; zona wisata air, yaitu zona yang memanfaatkan setu yang berada di kawasan dan dilengkapi dengan perahu-perahu air; terakhir, zona wisata industri yang memanfaatkan kawasan sekeliling setu maupun rumah adat untuk berjualan baik makanan, minuman, maupun suvenir khas Betawi (Windarsih). Zona-zona ini seutuhnya dikelola oleh pengelola Perkampungan Budaya Betawi Setu Babakan dengan tujuan meningkatkan daya tarik pariwisata perkampungan budaya. Bahkan perkampungan ini secara rutin menampilkan seni budaya Betawi (Murtani).

\section{Konstruksi Sosial}

Konstruksi sosial yang digunakan sebagai kerangka teoretis dalam artikel ini merujuk pada konsep konstruksi sosial yang dibangun oleh Peter L. Berger dan Thomas Luckmann. Teori ini berusaha menjelaskan dialektika antara individu dan masyarakat melalui tiga momentum, yaitu eksternalisasi, objektivikasi, dan internalisasi. Eksternalisasi dapat dimaknai suatu pencurahan kedirian manusia secara terus-menerus ke dalam dunia, baik dalam aktivitas fisis maupun mentalnya (Berger 4). Hari ini manusia yang terlahir ke dunia tidak perlu lagi membangun masyarakat, karena mereka sendiri telah terlahir di dalam sebuah masyarakat. Namun demikian, manusia tetap perlu membangun diri mereka dan memantapkan diri apakah mereka akan tetap berada pada masyarakat tersebut atau keluar darinya dan masuk ke dalam masyarakat lain, atau bahkan membuat masyarakat baru sesuai dengan apa yang mereka inginkan. Untuk memutuskan hal tersebut, manusia membutuhkan pengalaman hidup yang akan menjadi pencurahan atas diri mereka, baik secara fisik maupun mental. Keberadaan perkampungan budaya Setu Babakan dapat dimaknai dalam kaitannya dengan proses ini, yakni sebagai sebuah acuan bagi orang-orang yang terlahir ke dalam masyarakat Betawi dan mempelajari diri mereka sebagai 'Betawi'.

Dalam hal ini, komunitas Betawi melihat bahwa ada degradasi budaya di seluruh wilayah Jakarta yang menjadi asal-usul dan tempat tinggal mereka selama ini. Banyak masyarakat Betawi justru bermigrasi ke kota-kota lain di sekitar wilayah Jakarta, seperti Depok, Bekasi, Tangerang, dan lain-lain. Oleh sebab itu, komunitas Betawi bekerja sama dengan Pemerintah Provinsi DKI Jakarta untuk membentuk 'cagar budaya' di wilayah Jakarta. Sebelum dibentuknya Perkampungan Budaya Betawi Setu Babakan, Pemerintah Provinsi DKI Jakarta pernah membentuk cagar budaya Betawi di Condet, Jakarta Timur. Usaha ini tidak berlangsung lama karena banyak pendatang yang masuk justru tidak dilihat sebagai peluang pengembangan cagar budaya, tapi dimanfaatkan oleh individu-individu untuk meraih keuntungan 
dengan cara menjual tanah mereka. Oleh karena sebagian besar tanah di Condet dijual oleh penduduknya sendiri, padahal dasar cagar budaya Betawi di sana adalah pertanian, maka akhirnya cagar budaya ini dianggap gagal.

Selanjutnya, Sungai Ciliwung sebenarnya adalah lokasi yang tepat untuk membangun cagar budaya, mengingat asal-usul masyarakat Betawi tumbuh dan berkembang di bantaran sungai. Namun demikian, karena sempitnya lahan yang tersedia, khususnya di sekitar daerah aliran sungai, maka komunitas Betawi dan pemerintah provinsi merancang perkampungan budaya di sekitar setu. Pemilihan lokasi ini sendiri telah menunjukkan adanya eksternalisasi berkenaan dengan tempat tinggal masyarakat Betawi yang dipandang harus berada di sekitar lokasi air, seperti setu. Setu Babakan yang berada di Kelurahan Srengseng Sawah kemudian dianggap sebagai tempat yang potensial untuk pengembangan cagar budaya Betawi.

Momentum kedua dari dialektika masyarakat adalah objektivasi, yaitu disandangnya produk-produk aktivitas itu (Berger 4). Dalam hal ini terjadi pelembagaan, yaitu pengaturan secara kompleks tatanan sosial untuk menjadi pedoman individu-individu yang tergabung di dalamnya. Budaya Betawi adalah wujud dari objektivasi yang telah dibentuk oleh intelektual dan elite, baik tradisional maupun modern, sehingga hari ini menjadi sebuah institusi kebudayaan yang memberikan pedoman hidup manusia, khususnya manusia yang tergabung atau yang akan tergabung dalam masyarakat Betawi.

Perancangan Perkampungan Budaya Betawi Setu Babakan bukan sekadar upaya konstruksi yang muncul sebagai museum belaka, tapi juga memunculkan kondisi sosial atau dasar kehidupan yang perlu dilestarikan bagi masyarakat Betawi. Kondisi ini dibangun dengan perancangan zona-zona. Telah dikemukakan sebelumnya, terdapat dua pembagian zona, yaitu zona dinamis dan zona statis. Zona dinamis adalah kawasan permukiman yang dihuni oleh penduduk. Dikatakan zona dinamis karena pada dasarnya pengelola perkampungan tidak dapat mengatur kawasan ini. Terlebih, masyarakat Srengseng Sawah yang menjadi bagian dari Perkampungan Budaya Betawi Setu Babakan telah ada dan tinggal di sana sebelum cagar budaya ini dibentuk. Namun demikian, terdapat satu zona yang diatur oleh pemerintah setempat, yaitu zona ekonomi. Dalam hal ini, pihak pengelola tidak mengatur karena tidak memiliki ketetapan. Adapun pemerintah memiliki ketetapan dalam mengelola pedagang-pedagang kecil yang tumbuh di sekitar setu sebagai perwujudan perekonomian kecil.

Zona kedua adalah zona statis. Dikatakan statis bukan berarti tidak memiliki perkembangan, melainkan memiliki ketetapan dalam pengelolaan dan sepenuhnya diatur oleh pengelola Perkampungan Budaya Betawi Setu babakan. Adapun yang termasuk zona ini adalah zona kesenian, zona wisata air, zona sejarah berupa museum, zona agro, dan zona industri. Di zona kesenian telah dijadwalkan berbagai kegiatan kebudayaan mulai dari yang rutin hingga acara-acara tertentu.

Ketiga, internalisasi, yaitu peresapan kembali realitas oleh manusia yang kemudian mentransformasikannya sekali lagi dari struktur-struktur dunia objektif ke dalam struktur-struktur kesadaran subjektif (Berger 5). Dengan kata lain, setelah manusia membentuk masyarakat, maka dasar-dasar pembentukan masyarakat tersebut kembali dihayati dan diresapi. Selanjutnya, manusia memiliki harapan lebih terhadap masyarakat yang mereka bentuk, yaitu sebagai dunia kehidupan bagi keturunan mereka. Berger dan Luckmann mengungkapkan bahwa hanya dengan 
pengalihan dunia sosial kepada generasi baru maka dialektika sosial yang mendasar itu tampil dalam totalitasnya (Berger and Luckmann 84). Oleh sebab itu, mereka melakukan proses pengalihan pengetahuan atas lembaga atau masyarakat yang mereka hayati sekarang kepada generasi baru mereka, yaitu melalui proses yang disebut sosialisasi.

Sosialisasi diberikan kepada generasi baru melalui dua cara, yaitu sosialisasi primer dan sosialisasi sekunder. Sosialisasi dikatakan primer jika generasi baru mendapatkan pengetahuan secara langsung dari orang tua mereka. Sebaliknya, dikatakan sekunder jika generasi baru mendapatkan pengetahuan dari orang di luar orang tuanya (Pramudita 37). Proses pengalihan ini pada dasarnya tidak semata-mata wujud keegoisan generasi lama yang menuntut generasi baru untuk meneruskan lembaga yang telah mereka bentuk, namun perlu dipahami sebagai pencarian peranan sosial yang akan dipegang oleh generasi baru di dalam masyarakat sebagai tanda keanggotaannya.

Sebagai usaha internalisasi, pengelola Perkampungan Budaya Betawi Setu Babakan menghimbau dan menyosialisasikan kepada masyarakat Srengseng Sawah untuk ikut ambil bagian dalam pengembangan perkampungan budaya Betawi dengan cara turut membentuk rumahnya atau setidaknya menggunakan ornamen yang mencirikhaskan rumah adat Betawi. Hal ini untuk memperkuat representasi masyarakat Betawi di sekitar Perkampungan Budaya Betawi Setu Babakan. Dalam internalisasi ini, sebagian rumah masyarakat Srengseng Sawah, meskipun bukan merupakan rumah adat dan memiliki gaya arsitektural modern, telah menggunakan gigi balang yang berada di tepian atap rumah sebagai representasi rumah khas Betawi.

Kehidupan sehari-hari dimaksudkan sebagai penampakan dari perulangan tindakan manusia itu sendiri (Pramudita 21). Meskipun manusia melakukan tindakan yang sama setiap harinya, namun tindakan mereka tersebut bukanlah rutinitas atau kebiasaan belaka, melainkan pengalaman hidup yang akan dirasakan dalam keseharian mereka, merujuk pada nilai dan tata cara hidup yang mereka hayati sebagai bagian dari masyarakat. Selain itu, konsep ini juga menunjukkan kemungkinan tindakan yang tidak muncul dalam keseharian, namun akan muncul pada pengalaman yang serupa. Dunia kehidupan sehari-hari tidak hanya diterima begitu saja sebagai kenyataan oleh anggota masyarakat, namun juga satu dunia yang berasal dari pikiran-pikiran dan tindakan-tindakan mereka, dan dipelihara sebagai yang 'yang nyata' oleh pikiran dan tindakan itu (Berger and Luckmann 28).

Pada akhirnya, meskipun sebagian masyarakat Srengseng Sawah bukan masyarakat Betawi, namun adanya kawasan Perkampungan Budaya Betawi Setu Babakan membangun kesadaran bahwa mereka, baik secara langsung maupun tidak langsung, merupakan bagian dari masyarakat Betawi. Dengan demikian, masyarakat Betawi muncul sebagai kehidupan sehari-hari masyarakat Srengseng Sawah.

\section{SIMPULAN}

Kehidupan sehari-hari masyarakat Srengseng Sawah dimulai dengan adanya eksternalisasi dari komunitas Betawi dan Pemerintah Provinsi DKI Jakarta yang membentuk cagar budaya di Setu Babakan. Pembentukan zona-zona di Perkampungan Budaya Betawi Setu Babakan merupakan bentuk dari objektivasi yang 
dibentuk di perkampungan budaya ini. Adapun zona-zona tersebut antara lain zona dinamis sebagai pemukiman dan kawasan ekonomi masyarakat Srengseng Sawah, serta zona statis yang dibangun oleh pengelola Perkampungan Budaya Betawi Setu Babakan, meliputi zona kesenian, sejarah, wisata air, wisata agro, dan industri. Sebagai wujud pengakuan dan keikutsertaan masyarakat dalam upaya pelestarian budaya Betawi, mereka membangun rumah mereka sebagai representasi budaya Betawi dengan menggunakan ornamen gigi balang di bagian tepi atap rumah.

\section{UCAPAN TERIMA KASIH}

Terima kasih kepada Lembaga Penelitian dan Pengabdian kepada Masyarakat Univ. Indraprasta PGRI yang telah mendanai penelitian ini melalui Bantuan Dana Unindra Gasal 2018/2019, SK. Nomor: 1300/SP3/KP/LPPM/ UNINDRA/IX/2018.

\section{DAFTAR PUSTAKA}

Abercrombie, Nicholas, et al. Kamus Sosiologi. Translated by Desi Noviyani, Pustaka Pelajar, 2010.

Berger, Peter L. Langit Suci: Agama Sebagai Realitas Sosial. LP3ES, 1991.

Berger, Peter L., and Thomas Luckmann. Tafsir Sosial Atas Kenyataan: Risalah Tentang Sosiologi Pengetahuan. Translated by Hasan Basari, LP3ES, 1990.

Erwantoro, Heru. "Etnis Betawi: Kajian Historis." Patanjala: Jurnal Penelitian Sejarah Dan Budaya, vol. 6, no. 2, 2014, pp. 179-92, doi:http://dx.doi.org/10.30959/patanjala.v6i2.179.

Hidayah, Zulyani. Ensiklopedi Suku Bangsa Di Indonesia. Yayasan Pustaka Obor Indonesia, 2015.

Malik, Farmawati. "Posisi Pariwisata Perkampungan Budaya Betawi Setu Babakan." Jurnal Sains Terapan Pariwisata, vol. 2, no. 1, 2017, pp. 1-15, http://journal.polteksahid.ac.id/index.php/jstp/article/view/38.

Megawanti, Priarti. "Persepsi Masyarakat Setu Babakan Terhadap Perkampungan Budaya Betawi Dalam Upaya Melestarikan Kebudayaan Betawi." Sosio E-Kons, vol. 7, no. 3, 2015.

Murtani, Hanafi. “Revitalisasi Kearifan Budaya Betawi Dalam Memperkuat Ketahanan Budaya Nasional." WACANA: Jurnal Ilmiah Ilmu Komunikasi, vol. 13, no. 3, 2017, pp. 277-87, doi:https://doi.org/10.32509/wacana.v13i3.154.

Pramudita, Pandu. Konstruksi Identitas Dan Dialektika Anggota Paguyuban Ngesti Tunggal (Pangestu) Dalam Kehidupan Sehar-Hari. Universitas Gadjah Mada, 2015.

Rahmani, M. Makki. Pemikiran Plitik Masyarakat Betawi Pasca Rezim Soeharto. Jurusan Pemikiran Politik Islam Fakultas Usuluddin Universitas Islam Negeru Syarif Hidayatullah Jakarta, 2005. 
Saidi, H. Ridwan. Babad Tanah Betawi. PT Gria Media Prima, 2002.

Taylor, Jean Gelman. Kehidupan Sosial Di Batavia: Orang Eropa Dan Eurasia Di Hindia Timur. Masup Jakarta, 2009.

Windarsih, Ana. “Memahami 'Betawi' Dalam Konteks Cagar Budaya Condet Dan Setu Babakan." Jurnal Masyarakat Dan Budaya, vol. 15, no. 1, 2013, pp. 177-200, doi:http://dx.doi.org/10.14203/jmb.v15i1.146. 